\title{
Eccentric Reluctance and Permanent Magnets Synchronous Machines Comparison
}

\author{
Hanafy Mahmoud, Nicola Bianchi, Michele Degano, Mahir Al-Ani, and Chris Gerada.
}

\begin{abstract}
This paper deals with a comparative study between reluctance (REL), permanent magnet assisted reluctance (PMAREL), and surface mounted permanent magnet synchronous machines with rotor eccentricity. Static, dynamic, and combined eccentricity cases are considered. For the sake of generality, this comparison is carried out at different levels of airgap flux density, as different current angles, different permanent magnet (PM) materials, and different number of magnetic poles. Additionally, different stator windings arrangements, i.e, distributed and fractional slot concentrated windings are taken into account. Besides, different rotor geometries of REL and PMAREL machines are included. As a case of study, 36-slot machine is analyzed, considering three flux barriers per pole, however, the study can be applied to any machine geometry.

Due to the structural criticality of the rotor iron ribs of the REL machines, the impact of the eccentricity on the mechanical stress acting on those ribs and the deformation of the rotor is studied.
\end{abstract}

Index Terms-Reluctance synchronous machine, Permanent magnet assisted reluctance machine, Surface mounted permanent magnet machine, Eccentricity, Finite element analysis, Mechanical stresses, Structural analysis, Deformation analysis.

\section{INTRODUCTION}

Manufacturing imprecisions of electrical machines, such as shaft bow, mass unbalance, bearing tolerance, and lamination tolerance are common during the manufacturing process. These imprecisions could result in several types of rotor eccentricity, in which magnetic, dynamic and structural problems can occur in the electrical machine [1]-[3].

In the literature, the impact of eccentricity on the induction machine performance is reported in [2], [4], [5], besides, the eccentric surface mounted permanent magnet (SPM) machines are studied in [6]-[10]. However, the literature is showing that the magnetic performance of the eccentric reluctance (REL) and permanent magnet assisted reluctance (PMAREL) synchronous machines are only marginally investigated in [11]-[13]. Although there are several comparisons between the performance of REL, PMAREL, and SPM synchronous machines, with cylindrical rotor [14], [15], a detailed and wider

H. Mahmoud is with the Department of Electrical and Electronic Engineering, University of Nottingham, NG72RD, Nottingham (UK), and also with the Department of Electrical Power and Machines, Cairo University, 12613 Giza, Egypt (e-mail: eng.hanafy4@yahoo.com, Hanafy.Mahmoud@nottingham.ac.uk). N. Bianchi is with the Department of Industrial Engineering, University of Padova, 35131 Padova, Italy (email: nicola.bianchi@unipd.it; nicola.bianchi@dii.unipd.it). M. Degano and C. Gerada are with the Department of Electrical and Electronic Engineering, University of Nottingham, NG72RD, Nottingham (UK), and also with the University of Nottingham Ningbo China, Ningbo, China. (e-mail: michele.degano@nottingham.ac.uk), (e-mail: chris.gerada@nottingham.ac.uk) M. Al-Ani with the Department of Electrical and Electronic Engineering, University of Nottingham, UK (e-mail: mahir.al-ani@nottingham.ac.uk).

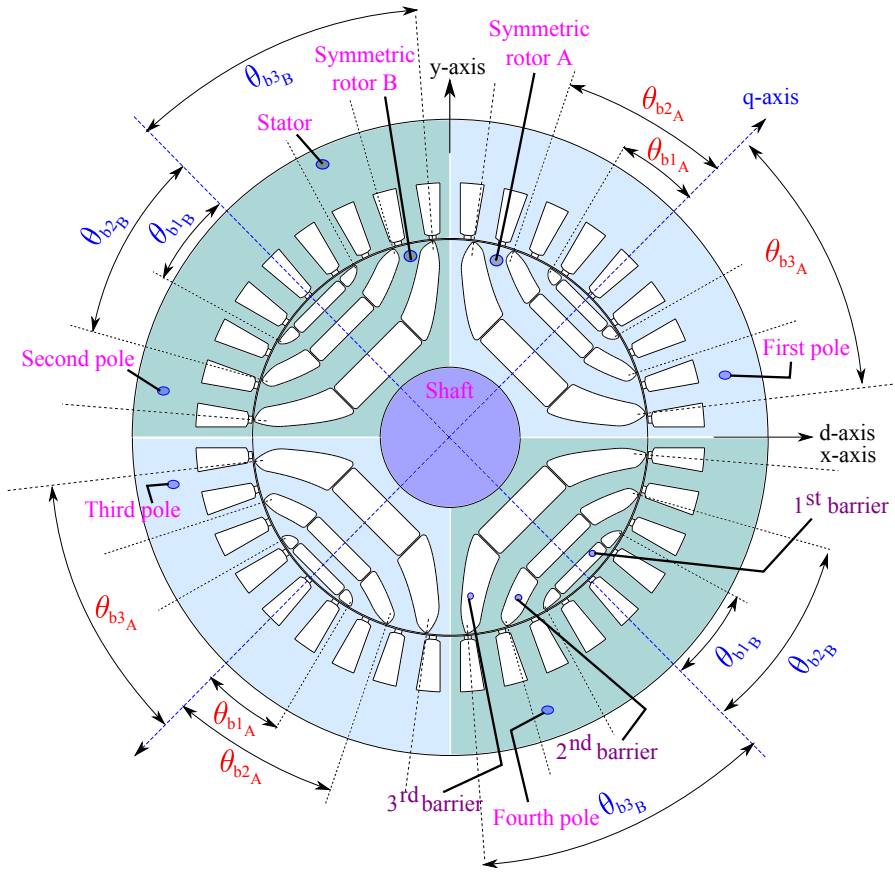

Fig. 1: Cross section showing of 4 pole REL/PMAREL machine with asymmetric rotor, which results from combining both symmetric rotor A (as shown in the first pole), and symmetric rotor B (as shown in the second pole).

comparison among these machines at different eccentricity cases is missing. In [16]-[18], comparisons between eccentric PMAREL and SPM synchronous motor are reported, however, those comparisons had not consider all possible eccentricity cases, lacking of generality. In addition, the REL motor has not been included in those comparisons.

The mechanical/structural analysis of the eccentric REL and PMAREL synchronous machines is not reported in the literature. These analyses are necessary to study the impact of different eccentricity scenarios on mechanical stresses acting on the rotor iron ribs, i.e., the rotor iron parts bordered by the flux-barriers, as shown in Fig. 1. Hence, the design safety factor of the iron ribs thicknesses can be checked if it covers the eccentricity impact or not [19]-[21].

To fill these gaps, this paper deals with the comparison between the three machines, in different eccentricity cases, aiming to draw useful design consideration and highlighting what are the eccentricity effects. For a fair comparison, the main geometry, number of poles, stator winding arrangement, and operating conditions are set to be the same for the three machines. For the sake of a generality, the comparison are 
repeated for other machines with different number of poles, stator windings (distributed and concentrated windings), and different types of PMs (Ferrite and $\mathrm{NdFeB}$ ), particularly for PMAREL and SPM motors, as well as with different rotor geometries, in particular, REL and PMAREL synchronous machines. Besides, the comparison is carried out for wide range of the operating current angles.

Finally, structural analysis of cylindrical and eccentric REL machine is conducted. The stress acting on the iron ribs due to both centrifugal and radial magnetic force are computed separately. This helps to understand the eccentricity impact on both forces components. Furthermore, the rotor deformation is studied for both cylindrical and eccentric rotors structures.

In static eccentricity case, the rotor axis is shifted from the stator axis and it rotates around its own center, as shown in Fig. 2 (a). In dynamic eccentricity case, the rotor axis is shifted from the stator axis and it rotates around the stator center, as shown in Fig. 2 (b). Whereas, in the combined eccentricity case, the rotor rotates around another different point. In this paper, as in Fig. 2 (c), it is considered in the middle of the stator and rotor axes.

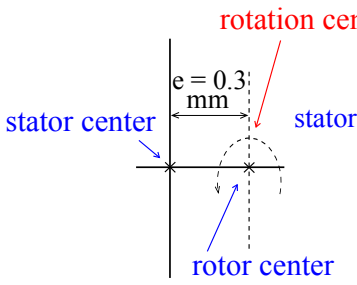

(a)

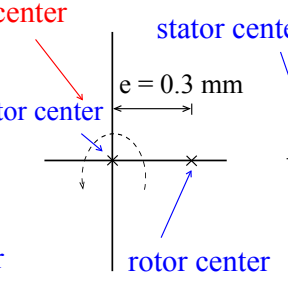

(b)

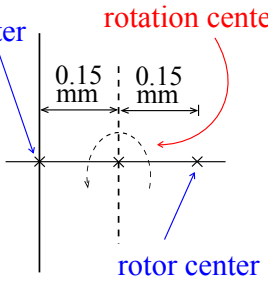

(c)
Fig. 2: Different cases of the rotor eccentricity. (a) static eccentricity, (b) dynamic eccentricity, and (c) combined eccentricity.

TABLE I: Geometrical data of the three machines.

\begin{tabular}{lcc}
\hline Stack length & $L_{s t k}$ & $40 \mathrm{~mm}$ \\
Inner stator radius & $R_{s}$ & $62.5 \mathrm{~mm}$ \\
Number of pole pairs & $p_{s}$ & 2 \\
Number of slots & $Q_{s}$ & 36 \\
Air-gap length for REL/PMAREL & $g_{R E L}$ & $0.35 \mathrm{~mm}$ \\
Sleeve thickness (SPM) & $g_{\text {sleeve }}$ & $0.15 \mathrm{~mm}$ \\
Air-gap length for SPM, i.e., $g+g_{\text {sleeve }}$ & $g_{S P M}$ & $0.5 \mathrm{~mm}$ \\
Symmetric rotor A 1 ${ }^{\text {st }}$ barrier end angle & $2 \theta_{b 1_{A}}$ & 28 degree \\
Symmetric rotor A 2 ${ }^{\text {nd }}$ barrier end angle & $2 \theta_{b 2_{A}}$ & 53 degree \\
Symmetric rotor A 3 ${ }^{\text {rd }}$ barrier end angle & $2 \theta_{b 3_{A}}$ & 77 degree \\
Symmetric rotor B 1 ${ }^{\text {st }}$ barrier end angle & $2 \theta_{b 1_{B}}$ & 32 degree \\
Symmetric rotor B 2 ${ }^{r d}$ barrier end angle & $2 \theta_{b 2_{B}}$ & 57 degree \\
Symmetric rotor B 3 ${ }^{r d}$ barrier end angle & $2 \theta_{b 3_{B}}$ & 81 degree \\
Rotor radius (SPM) & $R_{r}$ & $57 \mathrm{~mm}$ \\
Magnet thickness (SPM) & $h_{m}$ & $5 \mathrm{~mm}$ \\
Magnet radius (SPM) & $R_{m}$ & $62 \mathrm{~mm}$ \\
Pole-arc to pole pitch ratio (SPM) & $\alpha_{p}$ & 0.67 \\
Remanent flux density (SPM) & $B_{r e m}$ & $0.905 \mathrm{~T}$ \\
Magnet Relative permeability (SPM) & $\mu_{r}$ & 1.08 \\
\hline
\end{tabular}

The paper is organized as follows:

- due to the common specific geometric features between the REL, and PMREL machines, as the existing of the flux-barriers, different rotor geometries (symmetric and asymmetric rotors), they will be compared together at the beginning without considering the SPM machine. Skipping the SPM in this comparison helps to apply a general comparison among the REL, and PMREL machines considering different flux-barriers dimensions, different rotor geometries, and different PMs (Ferrite and $\mathrm{NdFeB}$ ) excitations inside the flux-barriers of the PMAREL, at different eccentricity cases. These comparisons are presented in section. III.

- The SPM machine is compared with the REL, Ferrite PMREL, and NdFeB PMAREL machines in terms of different stator windings arrangements and different number of poles. These comparisons are reported in section. IV.

- Finally, structural and deformation analyses are applied on the REL and PMAREL machines in eccentricity case, as discussed in section. V. The impact of the eccentricity on the stresses acting on the critical mechanical parts of the REL machine is studied.

\section{Theoretical Analyses Literature Review}

A wide investigation of the theoretical models of both REL and PMAREL machines is presented in [11], [12], [23], and [13]. Those models are general and valid for different stator winding arrangements, number of poles, and number of slots. Besides, they can be applied for a rotor with general number of the flux-barriers, not only three barriers, as shown in [11], [12] and [23]. It has been proven that the analysis presented in [11] and [23] works for any end angles of the rotor flux-barriers. As it can be noted in [13], the machine non-linearity, as the stator slotting effect and the magnetic saturation of the motor iron are considered analytically. Then, the FE and the experimental validation of the theoretical analyses is reported in [13]. In addition, this non-linear analytical model is extended to the eccentricity case and again it is validated by the FE analyses and the experimental measurements.

Analogously, the SPM machine theoretical analyses are carried out in the literature, as reported in [10], [8], [23], and [24], considering both cylindrical and eccentricity cases. Additionally, the 3D FE and experimental validation of these analytical models is reported in [24] and [10], respectively.

\section{COMPARISON BETWEEN REL AND PMAREL MOTORS}

The radial force acting on the whole rotor and the rotor islands of both REL, Ferrite and NdFeB PMAREL motors have been computed. Fig. 3 shows the computations of the radial magnetic force acting on each rotor island by integrating the Maxwell stress tensor over an arc in the middle of the airgap in front of each rotor island. The computation of these magnetic forces have been applied at the rotor position when the radial force is maximum. The geometrical data of both REL or PMAREL, shown in Fig. 1, are reported in Table I.

Two different rotor geometries of REL and PMAREL motors are considered. They are: (a) symmetric rotor (SR) and (b) asymmetric (Machaon) rotor (ASR). Both REL and PMAREL motors are characterized by three flux barriers per pole. In case of SR geometry, the flux-barriers have the same dimensions for all poles. Two symmetric rotors are considered to highlight the flux barrier dimensions in this study. They 


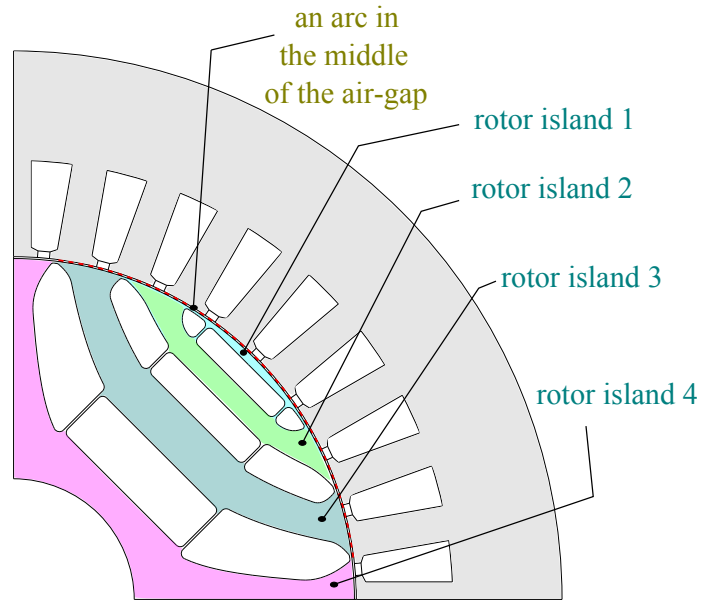

Fig. 3: Sketch representing the method for computing the radial forces acting on the third flux barrier (values calculated in the airgap middle region).

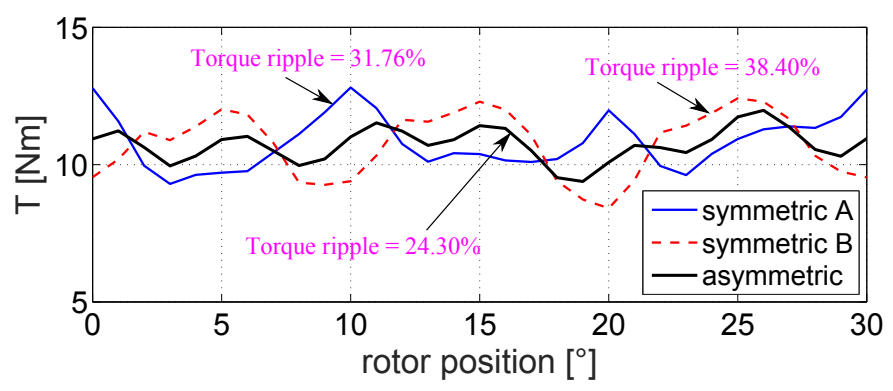

Fig. 4: The electromagnetic torque behaviour of REL machine, considering symmetric rotor A, B, and asymmetric rotor, versus the rotor position.

are called symmetric rotor $\mathrm{A}(\mathrm{SR}-\mathrm{A})$ and symmetric rotor $\mathrm{B}$ $(\mathrm{SR}-\mathrm{B})$. The flux-barrier angles of $\mathrm{SR}-\mathrm{B}$ are higher than those of SR-A, as shown in Table I. The third rotor geometry is an ASR with flux barrier dimensions of the first and third poles as those of SR-A, besides, the flux-barriers of the second and the fourth poles are as those of SR-B. This asymmetry is adopted to minimize one or more torque ripple harmonics, as can be noted from Fig. 4.

\section{A. Comparison in healthy case (no eccentricity)}

The REL, Ferrite PMAREL, and NdFeB PMAREL motors with cylindrical rotors (no eccentricity) are compared together in terms of the radial forces acting on the overall rotor and the rotor islands. The three different rotor geometries are considered in this comparison, which are $\mathrm{SR}-\mathrm{A}, \mathrm{SR}-\mathrm{B}$, and ASR. From Table II, it can be noted that, the radial forces are distributed evenly over the poles, offsetting to each other for both SR-A and SR-B. Besides, in case of ASR, the forces acting on the rotor islands of the second and fourth pole are different than those acting on the rotor islands of the first and third pole, due to the diversity of flux barriers. Since the forces are two by two equal and in opposite direction, the resultant forces acting on the overall rotors of the three machines are always very low. Therefore, it can be concluded that the magnetic radial force acting on the overall rotors of the three machines can be approximated to be zero for three rotor geometries.

As can be noted from Table II, there are no significant difference between the radial forces acting on the rotor islands of both REL and Ferrite PMAREL machines. This because the Ferrite PM is a low energy PM and is used only for saturating the rotor ribs to improve the power factor and is not used to increase the machine magnetic loading. Thus, it has no significant impact on the air-gap flux density in front to the rotor islands, and hence it has no significant impact on the radial magnetic forces acting on those islands. This conclusion has been achieved for the SR-A, SR-B, and the ASR.

Furthermore, comparing the radial forces acting on the rotor islands of both REL and NdFeB PMAREL machines, it can be noted that the magnetic force acting on first rotor island of SR - A, SR-B, and ASR is increased by $180 \%, 210 \%$, and $240 \%$, respectively. Referring to the second rotor island, the force is increased by $12 \%, 3 \%$, and $43 \%$, respectively. Besides, the force acting on the third island is increased by $6 \%,-0.5 \%$, and $13 \%$, respectively. From the previous numbers, it can be concluded that the most affected rotor island by inserting the $\mathrm{NdFeB}$ is the first/outer island, because the air-gap flux density in front of this island is increased significantly with respect to the other two island, due to the high percentage of NdFeB PM affecting the first barrier than the other two barriers.

\section{B. Comparison in static eccentricity case}

This section deals with the static eccentricity shown in Fig. 2 (a). Both REL and PMAREL machines have the same eccentricity distance, electric loading, and current angle. The latter is equal to $60^{\circ}$ for both motors, where the maximum torque per ampere (MTPA) occurs.

The radial force acting on the whole rotor of REL and PMAREL (Ferrite and NdFeB) machines is shown in Fig. 5, Fig. 6, and Fig. 7, respectively. As expected, there is high force in $\mathrm{x}$-axis direction where there is minimum air-gap length. From these figures, it can be noted that the radial force acting on the SR - B is slightly lower than that acting on SR - A highlighting the effect of the flux-barrier dimensions on the radial force. It is also worth noticing the small difference between the SR - B and the ASR.

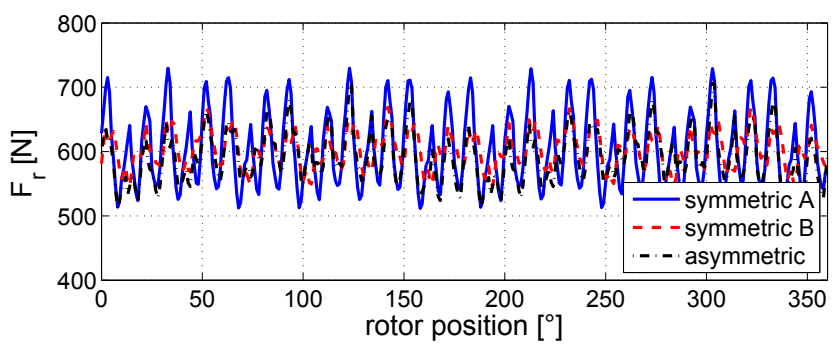

Fig. 5: Radial forces versus rotor position in case of REL motor, with static eccentricity $(e=0.3 \mathrm{~mm})$.

In addition, the inserted Ferrite and NdFeB PMs have no significant impact on the overall radial force acting on rotor and the bearings. Besides, the PM type has negligible effect 
TABLE II: Radial forces acting on the rotor islands of different rotor geometries of REL, Ferrite, and NdFeB PMAREL motors at $\theta_{m}=0^{\circ}$ in healthy case (with no eccentricity).

\begin{tabular}{cccccccccc}
\hline \multicolumn{10}{c}{$F_{r}[N]$} \\
\hline $\begin{array}{c}\text { Rotor geometry } \\
\text { Motor type }\end{array}$ & $\begin{array}{c}\text { SR - A } \\
\text { REL }\end{array}$ & $\begin{array}{c}\text { SR - B } \\
\text { REL }\end{array}$ & $\begin{array}{c}\text { ASR } \\
\text { REL }\end{array}$ & $\begin{array}{c}\text { SR - A } \\
\text { (Ferrite) }\end{array}$ & $\begin{array}{c}\text { SR - B } \\
\text { (Ferrite) }\end{array}$ & $\begin{array}{c}\text { ASR } \\
\text { (Ferrite) }\end{array}$ & $\begin{array}{c}\text { SR - A } \\
\text { (NdFeB) }\end{array}$ & $\begin{array}{c}\text { SR - B } \\
\text { (NdFeB) }\end{array}$ & $\begin{array}{c}\text { ASR } \\
\text { (NdFeB) }\end{array}$ \\
\hline $\begin{array}{c}\text { Pole 1 or 3 } \\
\text { rotor island 1 }\end{array}$ & 38.6 & 53.8 & 36.4 & 41.0 & 52.6 & 38.4 & 115 & 119 & 131 \\
rotor island 2 & 203 & 222 & 194 & 201 & 218 & 192 & 228 & 228 & 278 \\
rotor island 3 & 485 & 473 & 466 & 488 & 476 & 470 & 514 & 471 & 526 \\
\hline $\begin{array}{c}\text { Pole 2 or 4 } \\
\text { rotor island 1 }\end{array}$ & 38.6 & 54.4 & 54.2 & 41.1 & 53.3 & 53.4 & 115 & 121 & 108 \\
rotor island 2 & 203 & 225 & 226 & 201 & 222 & 222 & 228 & 233 & 268 \\
rotor island 3 & 486 & 478 & 479 & 488 & 480 & 481 & 515 & 477 & 507 \\
\hline
\end{tabular}

TABLE III: Radial forces acting on the rotor islands of different rotor geometries of REL, Ferrite, and NdFeB PMAREL motors with static eccentricity.

\begin{tabular}{|c|c|c|c|c|c|c|c|c|c|}
\hline & & & & & $r[N]$ (wo & t case) & & & \\
\hline $\begin{array}{c}\text { Rotor geometry } \\
\text { Motor type } \\
\theta_{m} \\
\end{array}$ & $\begin{array}{c}\text { SR - A } \\
\text { REL } \\
33^{\circ}\end{array}$ & $\begin{array}{l}\text { SR - B } \\
\text { REL } \\
52^{\circ} \\
\end{array}$ & $\begin{array}{l}\text { ASR } \\
\text { REL } \\
123^{\circ}\end{array}$ & $\begin{array}{c}\text { SR - A } \\
\text { (Ferrite) } \\
33^{\circ}\end{array}$ & $\begin{array}{c}\text { SR - B } \\
\text { (Ferrite) } \\
35^{\circ}\end{array}$ & $\begin{array}{c}\text { ASR } \\
\text { (Ferrite) } \\
124^{\circ}\end{array}$ & $\begin{array}{c}\mathrm{SR}-\mathrm{A} \\
(\mathrm{NdFeB}) \\
64^{\circ} \\
\end{array}$ & $\begin{array}{c}\mathrm{SR}-\mathrm{B} \\
(\mathrm{NdFeB}) \\
243^{\circ}\end{array}$ & $\begin{array}{c}\text { ASR } \\
(\mathrm{NdFeB}) \\
243^{\circ}\end{array}$ \\
\hline $\begin{array}{l}\text { Pole } 4 \\
\text { rotor island } 1 \\
\text { rotor island } 2 \\
\text { rotor island } 3\end{array}$ & $\begin{array}{l}41.3 \\
398 \\
\underline{813} \\
\end{array}$ & $\begin{array}{l}111 \\
387 \\
\underline{773} \\
\end{array}$ & $\begin{array}{l}47.0 \\
260 \\
547\end{array}$ & $\begin{array}{l}46.0 \\
384 \\
\underline{803} \\
\end{array}$ & $\begin{array}{l}57.4 \\
361 \\
736 \\
\end{array}$ & $\begin{array}{l}34.4 \\
259 \\
552 \\
\end{array}$ & $\begin{array}{l}207 \\
496 \\
922 \\
\end{array}$ & $\begin{array}{l}80.0 \\
188 \\
363\end{array}$ & $\begin{array}{c}79.9 \\
187 \\
359 \\
\end{array}$ \\
\hline $\begin{array}{l}\text { Pole } 1 \\
\text { rotor island } 1 \\
\text { rotor island } 2 \\
\text { rotor island } 3\end{array}$ & $\begin{array}{l}28.4 \\
247 \\
568\end{array}$ & $\begin{array}{l}57.1 \\
196 \\
465\end{array}$ & $\begin{array}{l}18.7 \\
135 \\
297\end{array}$ & $\begin{array}{l}27.0 \\
244 \\
574\end{array}$ & $\begin{array}{l}25.4 \\
247 \\
549\end{array}$ & $\begin{array}{l}9.74 \\
124 \\
308\end{array}$ & $\begin{array}{l}120 \\
248 \\
477\end{array}$ & $\begin{array}{l}121 \\
304 \\
575\end{array}$ & $\begin{array}{l}143 \\
322 \\
603\end{array}$ \\
\hline $\begin{array}{c}\text { Pole } 2 \\
\text { rotor island } 1 \\
\text { rotor island } 2 \\
\text { rotor island } 3\end{array}$ & $\begin{array}{l}19.6 \\
140 \\
307\end{array}$ & $\begin{array}{l}43.3 \\
133 \\
312\end{array}$ & $\begin{array}{l}39.9 \\
212 \\
452\end{array}$ & $\begin{array}{l}10.4 \\
132 \\
322\end{array}$ & $\begin{array}{l}13.2 \\
147 \\
330\end{array}$ & $\begin{array}{l}21.2 \\
202 \\
443\end{array}$ & $\begin{array}{l}101 \\
202 \\
383\end{array}$ & $\begin{array}{l}190 \\
528 \\
\underline{747} \\
\end{array}$ & $\begin{array}{l}188 \\
483 \\
801 \\
\end{array}$ \\
\hline $\begin{array}{l}\text { Pole } 3 \\
\text { rotor island } 1 \\
\text { rotor island } 2 \\
\text { rotor island } 3\end{array}$ & $\begin{array}{l}26.0 \\
204 \\
468\end{array}$ & $\begin{array}{l}62.7 \\
224 \\
522\end{array}$ & $\begin{array}{l}37.4 \\
370 \\
777 \\
\end{array}$ & $\begin{array}{l}16.1 \\
193 \\
467\end{array}$ & $\begin{array}{l}18.8 \\
195 \\
444\end{array}$ & $\begin{array}{l}42.0 \\
358 \\
770 \\
\end{array}$ & $\begin{array}{l}145 \\
328 \\
613\end{array}$ & $\begin{array}{l}98.4 \\
235 \\
451\end{array}$ & $\begin{array}{l}121 \\
245 \\
463\end{array}$ \\
\hline
\end{tabular}

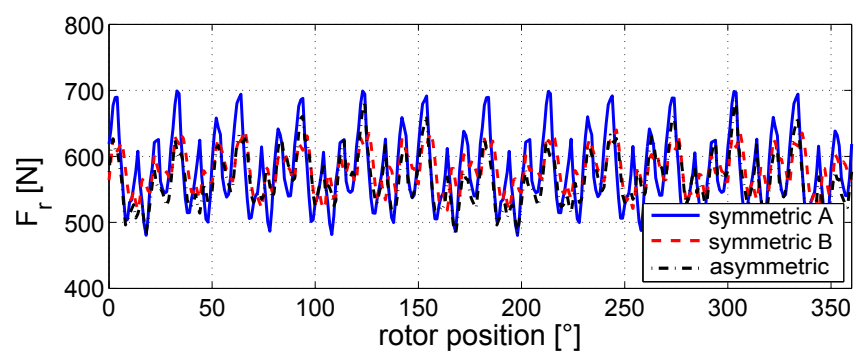

Fig. 6: Radial forces versus rotor position in case of PMAREL(with Ferrite PMs) motor, with static eccentricity $(e=0.3 \mathrm{~mm})$.

on this overall radial force. Thanks to the symmetric effect of the added PMs on all rotor poles, whereas the PMs increases the flux density not only in front of the two poles close to the minimum air-gap length, but also in front of the other two poles. Table III reports the comparison among REL, Ferrite PMAREL, and NdFeB PMAREL motors, in terms of the magnetic forces acting on the rotor islands, and hence the iron ribs, in case of static eccentricity. Referring to the rotor island 3 of the worst pole, from the underlined red values in Table III, it cab be observed that the Ferrite PMs there are no significant impact on the magnetic force acting on that

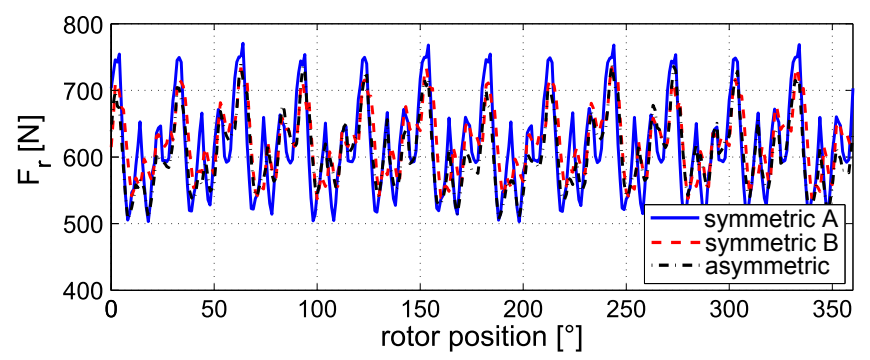

Fig. 7: Radial forces versus rotor position in case of PMAREL (with $\mathrm{NdFeB} \mathrm{PMs})$ motor, with static eccentricity $(e=0.3 \mathrm{~mm})$.

island. On the other side, the magnetic force acting on the corresponding island of SR - A is increased by $14 \%$, when $\mathrm{NdFeB} \mathrm{PMs}$ are inset in the flux-barriers. Besides, there is no significant difference (only $4 \%$ ) is noted in case of SR - B and ASR. The third rotor island is refereed because it is the most affected island by the static eccentricity force as shown in Table III), due to the wide integration range of the air-gap region in front to it during the magnetic pressure computation, and hence the force computation. 
TABLE IV: Radial forces acting on the rotor islands of different rotor geometries of REL, Ferrite, and NdFeB PMAREL motors with dynamic eccentricity.

\begin{tabular}{|c|c|c|c|c|c|c|c|c|c|}
\hline & & & & & $r[N]$ (wo & $t$ case) & & & \\
\hline $\begin{array}{c}\text { Rotor geometry } \\
\text { Motor type } \\
\theta_{m}\end{array}$ & $\begin{array}{l}\text { SR - A } \\
\text { REL } \\
273^{\circ}\end{array}$ & $\begin{array}{l}\text { SR - B } \\
\text { REL } \\
22^{\circ}\end{array}$ & $\begin{array}{l}\text { ASR } \\
\text { REL } \\
332^{\circ}\end{array}$ & $\begin{array}{c}\mathrm{SR}-\mathrm{A} \\
\text { (Ferrite) } \\
184^{\circ}\end{array}$ & $\begin{array}{c}\text { SR - B } \\
\text { (Ferrite) } \\
216^{\circ}\end{array}$ & $\begin{array}{c}\text { ASR } \\
\text { (Ferrite) } \\
332^{\circ}\end{array}$ & $\begin{array}{c}\mathrm{SR}-\mathrm{A} \\
(\mathrm{NdFeB}) \\
184^{\circ}\end{array}$ & $\begin{array}{c}\mathrm{SR}-\mathrm{B} \\
(\mathrm{NdFeB}) \\
3^{\circ}\end{array}$ & $\begin{array}{c}\text { ASR } \\
(\mathrm{NdFeB}) \\
332^{\circ}\end{array}$ \\
\hline $\begin{array}{l}\text { Pole } 1 \\
\text { rotor island } 1 \\
\text { rotor island } 2 \\
\text { rotor island } 3\end{array}$ & $\begin{array}{l}33.9 \\
333 \\
718\end{array}$ & $\begin{array}{l}90.0 \\
314 \\
669\end{array}$ & $\begin{array}{l}41.3 \\
299 \\
665\end{array}$ & $\begin{array}{l}36.2 \\
322 \\
731 \\
\end{array}$ & $\begin{array}{l}52.2 \\
315 \\
686 \\
\end{array}$ & $\begin{array}{l}41.7 \\
306 \\
676\end{array}$ & $\begin{array}{l}180 \\
418 \\
825 \\
\end{array}$ & $\begin{array}{l}165 \\
461 \\
712 \\
\end{array}$ & $\begin{array}{l}182 \\
433 \\
772 \\
\end{array}$ \\
\hline $\begin{array}{l}\text { Pole } 2 \\
\text { rotor island } 1 \\
\text { rotor island } 2 \\
\text { rotor island } 3\end{array}$ & $\begin{array}{l}19.3 \\
159 \\
359\end{array}$ & $\begin{array}{l}46.9 \\
151 \\
357\end{array}$ & $\begin{array}{l}38.1 \\
173 \\
368\end{array}$ & $\begin{array}{l}11.4 \\
145 \\
361\end{array}$ & $\begin{array}{l}17.1 \\
161 \\
371\end{array}$ & $\begin{array}{l}25.3 \\
162 \\
375\end{array}$ & $\begin{array}{l}109 \\
218 \\
408\end{array}$ & $\begin{array}{l}87.7 \\
202 \\
385\end{array}$ & $\begin{array}{l}90.1 \\
202 \\
381\end{array}$ \\
\hline $\begin{array}{l}\text { Pole } 3 \\
\text { rotor island } 1 \\
\text { rotor island } 2 \\
\text { rotor island } 3\end{array}$ & $\begin{array}{l}21.5 \\
161 \\
360\end{array}$ & $\begin{array}{l}49.7 \\
156 \\
360\end{array}$ & $\begin{array}{l}24.8 \\
158 \\
359\end{array}$ & $\begin{array}{l}11.4 \\
145 \\
363\end{array}$ & $\begin{array}{l}15.8 \\
155 \\
358\end{array}$ & $\begin{array}{l}15.1 \\
148 \\
370\end{array}$ & $\begin{array}{l}102 \\
218 \\
422\end{array}$ & $\begin{array}{l}83.3 \\
204 \\
402\end{array}$ & $\begin{array}{l}109 \\
218 \\
423\end{array}$ \\
\hline $\begin{array}{l}\text { Pole } 4 \\
\text { rotor island } 1 \\
\text { rotor island } 2 \\
\text { rotor island } 3\end{array}$ & $\begin{array}{l}37.4 \\
341 \\
719 \\
\end{array}$ & $\begin{array}{l}84.3 \\
311 \\
679 \\
\end{array}$ & $\begin{array}{l}61.0 \\
341 \\
698 \\
\end{array}$ & $\begin{array}{l}39.0 \\
319 \\
691\end{array}$ & $\begin{array}{l}42.4 \\
278 \\
612\end{array}$ & $\begin{array}{l}60.2 \\
333 \\
695 \\
\end{array}$ & $\begin{array}{l}180 \\
415 \\
742\end{array}$ & $\begin{array}{l}160 \\
393 \\
701\end{array}$ & $\begin{array}{l}165 \\
394 \\
714\end{array}$ \\
\hline
\end{tabular}

\section{Comparison in dynamic eccentricity case}

Referring to the dynamic rotor eccentricity described in Fig. 2 (b), the radial force acting on the overall rotor of REL and PMAREL (Ferrite and NdFeB) machines are shown in Fig. 8. The different rotor geometries are considered for both machines at the same eccentricity, current angle, and the same electric loading.

Once again, the radial force acting on the SR - B is lower than that acting on the SR - A and close to that acting on the ASR. Furthermore, the introduction of the Ferrite PMs within the flux-barriers yields a slight reduction of the radial force acting on overall the rotor. In case of introduction of $\mathrm{NdFeB}$ PMs, the radial force on overall the rotor is comparable with that in case of REL motor, as well.

The maximum radial forces acting on the different rotor islands of REL, Ferrite PMAREL, and NdFeB PMAREL motor are reported in Table IV. Similar to the previous subsection, referring to the rotor island 3 (from the underlined red values in Table IV), the same conclusion of the comparison in static eccentricity case is found in the dynamic eccentricity case.

\section{Comparison in combined eccentricity case}

The combined eccentricity occurs when the machine is subjected simultaneously to the static and dynamic eccentricity. The distance between the rotor and stator axes is constant in static and dynamic eccentricity cases. On the contrary, in combined eccentricity case, the relative position of the rotor axis is varied by varying the position of the rotor. This study assumes that the stator is shifted horizontally to the left hand side by $0.15 \mathrm{~mm}$ and the rotor axis is shifted horizontally to the right hand side by $0.15 \mathrm{~mm}$ at $\theta_{m}=0^{\circ}$. Therefore, the maximum distance between the stator and rotor axis is $e_{0}=0.3 \mathrm{~mm}$ at $\theta_{m}=0^{\circ}$. By increasing $\theta_{m}$ with the rotor rotation, this distance is reduced till to reach zero value at

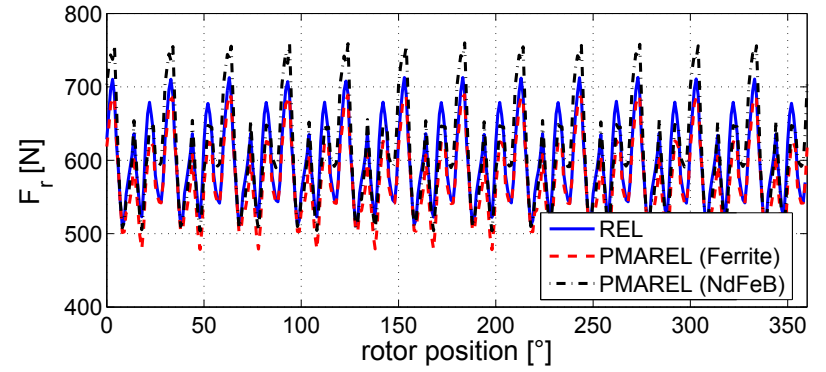

(a) symmetric rotor $\mathrm{A}$.

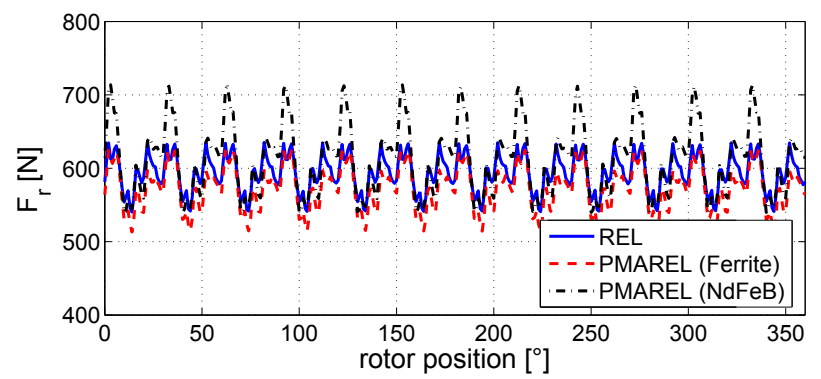

(b) symmetric rotor B.

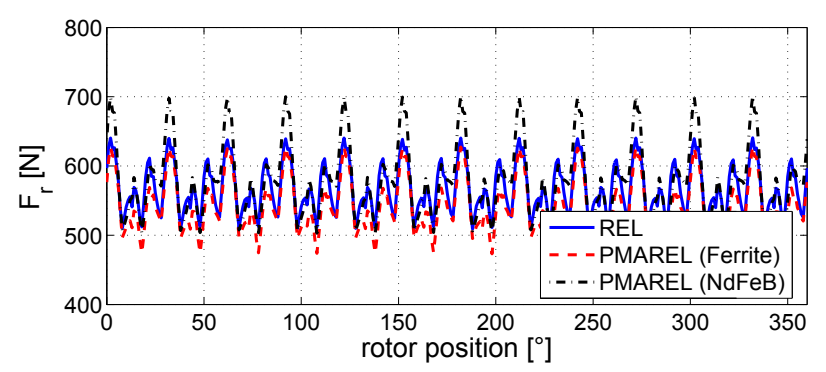

(c) asymmetric rotor.

Fig. 8: Radial forces acting on the rotor of REL, Ferrite PMAREL, and NdFeB PMAREL motors, with dynamic eccentricity $(e=0.3$ $m m$ ). 
TABLE V: Radial forces acting on the rotor islands of different rotor geometries of REL, Ferrite, and NdFeB PMAREL motors with combined eccentricity.

\begin{tabular}{|c|c|c|c|c|c|c|c|c|c|}
\hline & & & & & $r[N]$ (wo & t case) & & & \\
\hline $\begin{array}{c}\text { Rotor geometry } \\
\text { Motor type } \\
\theta_{m}\end{array}$ & $\begin{array}{l}\text { SR - A } \\
\text { REL } \\
3^{\circ}\end{array}$ & $\begin{array}{l}\text { SR - B } \\
\text { REL } \\
352^{\circ}\end{array}$ & $\begin{array}{l}\text { ASR } \\
\text { REL } \\
2^{\circ}\end{array}$ & $\begin{array}{c}\text { SR - A } \\
\text { (Ferrite) } \\
4^{\circ}\end{array}$ & $\begin{array}{c}\text { SR - B } \\
\text { (Ferrite) } \\
2^{\circ}\end{array}$ & $\begin{array}{c}\text { ASR } \\
\text { (Ferrite) } \\
2^{\circ}\end{array}$ & $\begin{array}{c}\mathrm{SR}-\mathrm{A} \\
(\mathrm{NdFeB}) \\
4^{\circ}\end{array}$ & $\begin{array}{c}\mathrm{SR}-\mathrm{B} \\
(\mathrm{NdFeB}) \\
2^{\circ}\end{array}$ & $\begin{array}{c}\text { ASR } \\
(\mathrm{NdFeB}) \\
2^{\circ}\end{array}$ \\
\hline $\begin{array}{l}\text { Pole } 1 \\
\text { rotor island } 1 \\
\text { rotor island } 2 \\
\text { rotor island } 3\end{array}$ & $\begin{array}{l}33.7 \\
329 \\
708\end{array}$ & $\begin{array}{l}93.5 \\
326 \\
684\end{array}$ & $\begin{array}{l}34.7 \\
297 \\
660\end{array}$ & $\begin{array}{c}35.2 \\
317 \\
71\end{array}$ & $\begin{array}{l}60.8 \\
332 \\
689\end{array}$ & $\begin{array}{l}42.4 \\
304 \\
671\end{array}$ & $\begin{array}{l}117 \\
410 \\
813\end{array}$ & $\begin{array}{l}179 \\
454 \\
759\end{array}$ & $\begin{array}{l}181 \\
426 \\
766\end{array}$ \\
\hline $\begin{array}{c}\text { Pole } 2 \\
\text { rotor island } 1 \\
\text { rotor island } 2 \\
\text { rotor island } 3\end{array}$ & $\begin{array}{l}20.1 \\
157 \\
354\end{array}$ & $\begin{array}{l}47.9 \\
155 \\
368\end{array}$ & $\begin{array}{l}38.4 \\
173 \\
366\end{array}$ & $\begin{array}{l}11.5 \\
144 \\
359\end{array}$ & $\begin{array}{l}25.7 \\
162 \\
375\end{array}$ & $\begin{array}{l}25.7 \\
162 \\
373\end{array}$ & $\begin{array}{l}108 \\
216 \\
405\end{array}$ & $\begin{array}{l}90.5 \\
201 \\
381\end{array}$ & $\begin{array}{c}90 \\
201 \\
379\end{array}$ \\
\hline $\begin{array}{c}\text { Pole } 3 \\
\text { rotor island } 1 \\
\text { rotor island } 2 \\
\text { rotor island } 3\end{array}$ & $\begin{array}{l}22.3 \\
163 \\
365\end{array}$ & $\begin{array}{l}47.8 \\
151 \\
353\end{array}$ & $\begin{array}{l}23.8 \\
158 \\
362\end{array}$ & $\begin{array}{l}11.5 \\
148 \\
371\end{array}$ & $\begin{array}{l}23.1 \\
166 \\
390\end{array}$ & $\begin{array}{l}14.6 \\
149 \\
372\end{array}$ & $\begin{array}{l}106 \\
220 \\
426\end{array}$ & $\begin{array}{l}86.4 \\
206 \\
411\end{array}$ & $\begin{array}{l}109 \\
219 \\
426\end{array}$ \\
\hline $\begin{array}{c}\text { Pole } 4 \\
\text { rotor island } 1 \\
\text { rotor island } 2 \\
\text { rotor island } 3\end{array}$ & $\begin{array}{l}37.1 \\
341 \\
721\end{array}$ & $\begin{array}{l}80.9 \\
299 \\
657\end{array}$ & $\begin{array}{l}59.1 \\
340 \\
695\end{array}$ & $\begin{array}{l}38.9 \\
320 \\
693\end{array}$ & $\begin{array}{l}58.2 \\
332 \\
701\end{array}$ & $\begin{array}{l}58.3 \\
332 \\
692\end{array}$ & $\begin{array}{l}181 \\
418 \\
750\end{array}$ & $\begin{array}{l}166 \\
408 \\
722\end{array}$ & $\begin{array}{l}166 \\
407 \\
696\end{array}$ \\
\hline
\end{tabular}

$\theta_{m}=180^{\circ}$ (i.e., when the stator and rotor axis are coincident). Then, by increasing $\theta_{m}$, the eccentricity distance increases again, until it returns to the maximum distance at $\theta_{m}=360^{\circ}$.

The eccentricity distance is a function of the rotor position $\theta_{m}$. It is given by:

$$
e\left(\theta_{m}\right)=e_{0} \cos \left(\frac{\theta_{m}}{2}\right)
$$

considering $\theta_{m}$ varying between $0^{\circ}$ and $180^{\circ}$.

$$
e\left(\theta_{m}\right)=e_{0} \cos \left(\frac{360^{\circ}-\theta_{m}}{2}\right)
$$

where $\theta_{m}$ varies from $180^{\circ}$ to $360^{\circ}$. Then, the maximum and minimum air-gap length are given by:

$$
\begin{aligned}
& g_{\text {min }}\left(\theta_{m}\right)=g_{0}-e\left(\theta_{m}\right) \\
& g_{\text {max }}\left(\theta_{m}\right)=g_{0}+e\left(\theta_{m}\right)
\end{aligned}
$$

From Fig. 9, it is noted that there is no significant change in the overall force acting on the rotor results from adding the Ferrite and NdFeB PMs within the flux-barriers.

Since, the rotor is horizontally shifted to the right hand side, the most stressed rotor islands are of poles 1 and 4, which agree with the results reported in Table V. From Table V, comparing REL and NdFeB PMAREL motors together, it can be concluded that, adopting NdFeB PMs within the fluxbarriers of SR - A, the radial forces acting on the rotor islands 1, 2 and 3 are increased by $245 \%, 25 \%$, and $15 \%$, respectively. Whereas the Ferrite PMs have no significant effect of the forces acting on the corresponding rotor islands. Analogously, for SR - B, the forces are increased by $430 \%$, $38 \%$, and $7 \%$ for the rotor islands, respectively. Moreover, in case of ASR, the forces are increased by $440 \%, 30 \%$, and $8 \%$, respectively. Again, the Ferrite PMs impact on the SR - B and ASR is negligible.

From Tables V and II (i.e, comparing the results of the combined eccentricity and the healthy case together), the effect

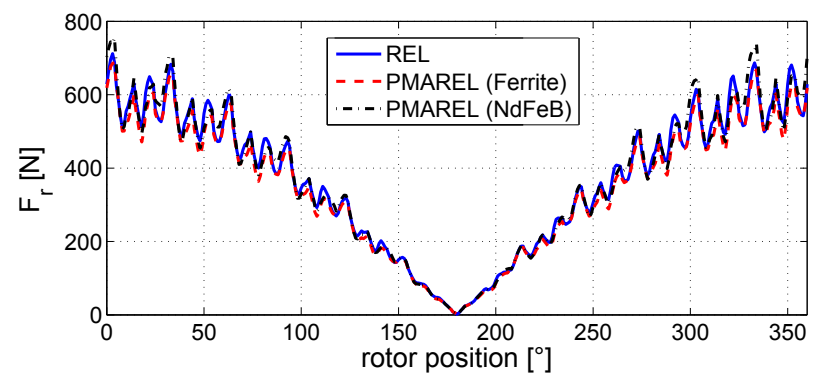

(a) symmetric rotor $\mathrm{A}$.

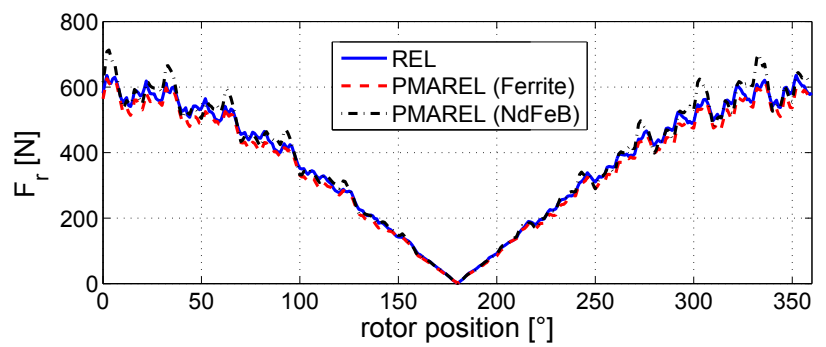

(b) symmetric rotor B

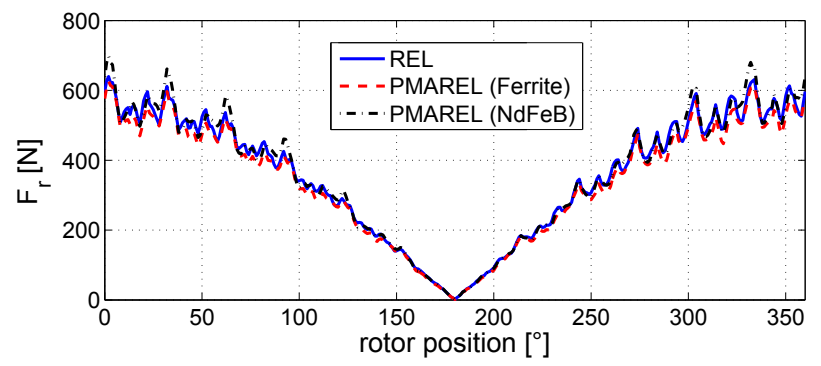

(c) asymmetric rotor.

Fig. 9: Radial forces acting on the rotor of REL, Ferrite PMAREL, and NdFeB PMAREL motors, with combined eccentricity $(e=0.3$ $m m$ ). 
of the mixed eccentricity on the radial forces acting on the rotor islands can be studied. Referring to the third island of $\mathrm{SR}-\mathrm{A}, \mathrm{SR}-\mathrm{B}$, and ASR, the magnetic force is increased by $48 \%, 43 \%$, and $45 \%$, respectively. The REL motor results are compared in the tables, as an example.

\section{COMPARISON OF SPM, PMAREL AND REL MOTOR}

Similarly, the radial force acting on the overall rotor of the SPM machines for all rotor position (from 0 to $360^{\circ}$ ) is computed in this section, as well as the maximum radial forces acting on the PMs. Fig. 10 shows a cross section of the SPM motor considered in this study. As mentioned before, for the purpose of fair comparison between the three motors, the analyzed SPM motor has the same main geometrical dimensions of the other two motors, as reported in Table I. Besides, the same distributed windings are fixed for the stator (36 slots 4 pole windings) for having the same stator MMF harmonic contents, as in case of REL and PMAREL motors.

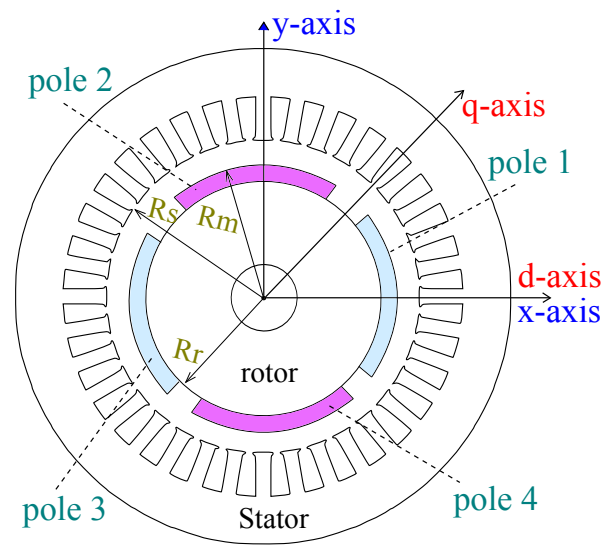

Fig. 10: Cross section of SPM machine under analysis.

\section{A. Comparison in healthy case (no eccentricity)}

Referring to SPM motor with cylindrical rotor, the radial force acting on each pole is computed. The results are reported in Table VI. It is noted that the force acting on the third pole compensates that acting on the first pole. Similarly, the force on the second pole almost cancels the force acting on the fourth pole. Therefore, the overall force on the rotor is equal to a few Newtons (can be approximated to zero). By comparing this motor with the REL and PMAREL motors, it is noted that, the three motors exhibit the same zero force on the whole rotor in no eccentricity case.

TABLE VI: Radial forces acting on the poles of the SPM motor at $\theta_{m}=0^{\circ}$ in healthy case (with no eccentricity).

\begin{tabular}{cccc}
\hline \multicolumn{4}{c}{$F_{r}$ acting on the PMs $[N]$} \\
\hline POLE 1 & POLE 2 & POLE 3 & POLE 4 \\
\hline 588.9 & 588.4 & 588.7 & 588.9 \\
\hline
\end{tabular}

\section{B. Comparison in static eccentricity case}

As mentioned before, to reduce the torque ripple of the PMAREL or REL motor, the asymmetric rotor geometry is preferred [22]-[24]. Besides, from Fig. 5, Fig. 6, and Fig. 7, it is noted that there is no significant difference between the radial forces acting on the whole rotor of both REL and PMAREL motors in different eccentricity cases (from 5\% to $10 \%$ considering the different rotor geometries). Consequently, SPM motor is compared with PMAREL motor with asymmetric rotor geometry. Table VII shows the maximum radial forces on the rotor of SPM, Ferrite PMAREL, and NdFeB PMAREL motors. It is noted that the radial force on the whole rotor of Ferrite PMAREL and NdFeB PMAREL is equal to $450 \%$ and $510 \%$ of that acting on whole rotor of SPM motor, respectively. This difference results from the specific geometrical features of studied motors topologies, as: (a) the magnetic air-gap length of the SPM motor is higher than that of the REL and PMAREL motors due to the sleeve or PMs cover thickness added to the mechanical air-gap length, as highlighted in Table I, (b) the sensitivity of both REL and PMAREL machines to the air-gap length, and hence, the eccentricity, with respect to the SPM machines because their dependency on the reluctance torque component.

TABLE VII: Worst radial forces acting on the rotor SPM, Ferrite PMAREL, and NdFeB PMAREL motors, with static eccentricity.

\begin{tabular}{cccc}
\hline & $\begin{array}{c}\text { SPM } \\
(\mathrm{NdFeB} \mathrm{PMs})\end{array}$ & $\begin{array}{c}\text { PMAREL } \\
(\text { Ferrite PMs }) \\
\theta_{m}=121^{\circ}\end{array}$ & $\begin{array}{c}\text { PMAREL } \\
(\text { NdFeB PMs })\end{array}$ \\
\hline$F_{r}[N]$ & 146 & $684^{\circ}$ & $\theta_{m}=243^{\circ}$ \\
\hline
\end{tabular}

Considering the maximum radial force on the rotor, whereas the rotor position is at $\left(\theta_{m}=121^{\circ}\right)$, the radial force acting on each pole is computed and reported in Table VIII. The fourth and the third poles are the most affected because they are close to the minimum air-gap length. However, the worst radial force is that acting on the fourth pole. By comparing Table VI (of the healthy case) and Table VIII, it can be observed that the radial force acting on this pole is increased by $12 \%$ due to the static eccentricity.

TABLE VIII: Radial forces acting on the poles of the SPM motor, with static eccentricity, at $\theta_{m}=121^{\circ}$.

\begin{tabular}{cccc}
\hline \multicolumn{4}{c}{$F_{r}$ acting on the PMs $[N]$} \\
\hline POLE 1 & POLE 2 & POLE 3 & POLE 4 \\
\hline 559.8 & 547.2 & 622.3 & 661.5 \\
\hline
\end{tabular}

As mentioned in the introduction, for the sake of the generality of this comparison, it is carried out at: 1) different operating conditions, 2) different stator winding configurations, 3) different number of poles, and 4) different rotor geometries, as considered in the previous section.

1) Different operating conditions: Referring to the vector diagram shown in Fig. 11, it can be noted that the current angle $\left(\alpha_{i}^{e}=\tan ^{-1}\left(i_{q} / i_{d}\right)\right)$ has an impact on the air-gap flux 


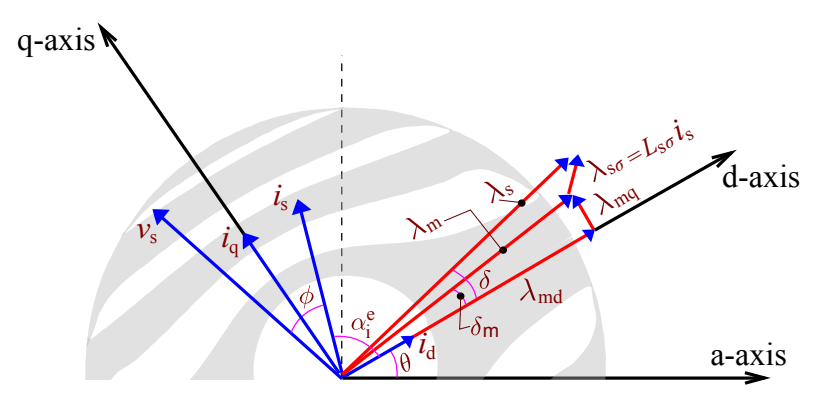

Fig. 11: Vector diagram of synchronous reluctance machines [26].

density. Therefore, the comparison between the three machines is carried out at different values of current angles, as shown in Fig. 12. It can be deduced, the unbalanced forces in case of PMAREL and REL motor are higher than that in case of SPM motor for the possible range of current angle due to the different sensitivity to the air-gap variation and the specific geometrical features which affect the magnetic air-gap length of the compared machines.

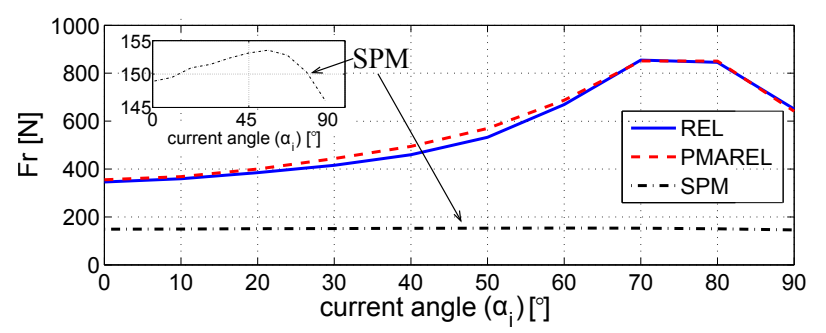

Fig. 12: Maximum radial forces versus current angle of REL, PMAREL, and SPM motors.

2) Different stator winding configurations: The previous comparison is carried out considering the distributed windings in the stator. Nevertheless, this comparison is repeated when fractional slot concentrated windings (FSCW) is adopted to identify which winding configuration is the worst in case of eccentricity. Due to the high unbalanced radial force for single layer FSCW at healthy case, as concluded in [12], the comparison is carried out only for double layer FSCW. As an example, 6-slot four-pole three motors are used for this comparison, as shown in Fig. 13. Hence, the radial force acting on SPM and PMAREL motor is equal to $116 \mathrm{~N}$ and $223 \mathrm{~N}$, respectively, as can be noted from Fig. 14. The same conclusion has been achieved as the distributed winding case.

3) Different number of poles: To ensure the generality of this comparison, the analysis is repeated for two different motors with six-pole. As an example, 36-slot 6-pole motors are analyzed, as shown in Fig. 15. The radial force on both SPM and PMAREL motor is $180 \mathrm{~N}$ and $1220 \mathrm{~N}$, respectively, as shown in Fig. 16 (a) and Fig. 16 (b). Once again, the radial force acting on the rotor of PMAREL motor is higher.

\section{Comparison in dynamic eccentricity case}

Similarly, the radial force acting on the rotor of the PMAREL motor is about $430 \%$ and $480 \%$ of that acting on the rotor of the SPM motor, in case of using Ferrite and $\mathrm{NdFeB}$

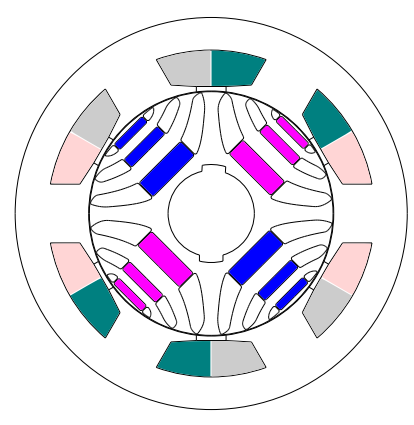

(a) PMAREL motor.

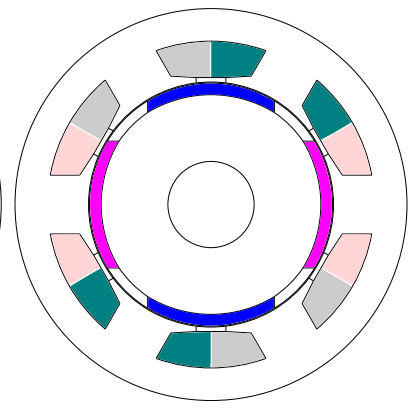

(b) SPM motor.
Fig. 13: Cross section of the compared 6 slot four pole (a) PMAREL and (b) SPM motors.

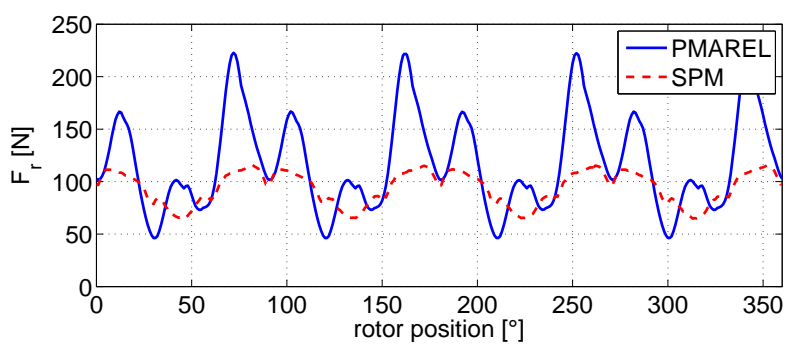

Fig. 14: The magnetic force behavior versus the rotor position for both 6-slot four-pole PMAREL and SPM motors, with static eccentricity case.

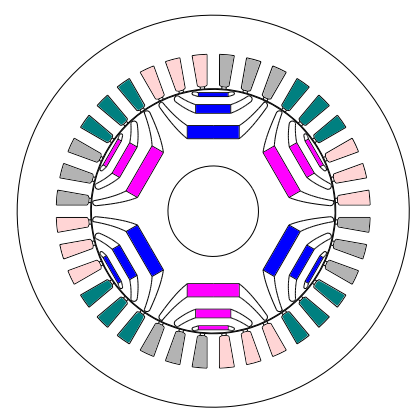

(a) PMAREL motor.

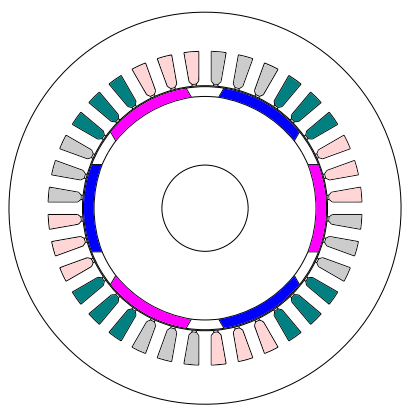

(b) SPM motor.
Fig. 15: Cross section of the compared six pole (a) PMAREL and (b) SPM motors.

PMs, respectively. The maximum force acting on the rotor of the SPM motor is at $\theta_{m}=240^{\circ}$. Table IX shows the radial force acting on each pole. The most affected PM is that of the first pole. From Table VI and Table IX, the force acting on that pole is increased by $10 \%$ due to the dynamic eccentricity.

TABLE IX: Radial forces acting on the poles of the SPM motor, with dynamic eccentricity, at $\theta_{m}=240^{\circ}$.

\begin{tabular}{cccc}
\hline \multicolumn{4}{c}{$F_{r}$ acting on the PMs $[N]$} \\
\hline POLE 1 & POLE 2 & POLE 3 & POLE 4 \\
\hline 648.2 & 584.7 & 536.1 & 593.2 \\
\hline
\end{tabular}

Once again, this comparison is carried out at the following conditions: 1) different current angles, 2) different stator 


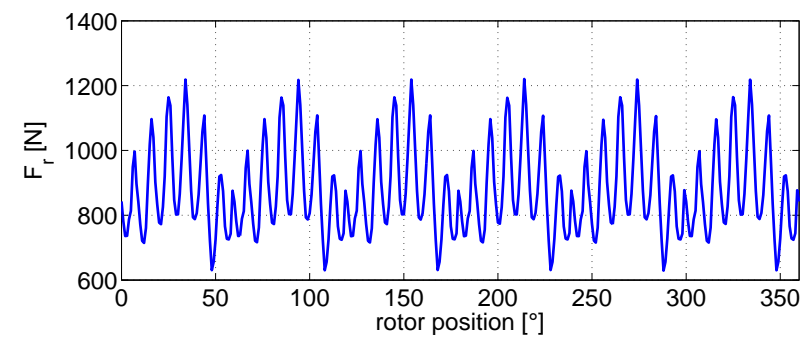

(a) PMAREL motor.

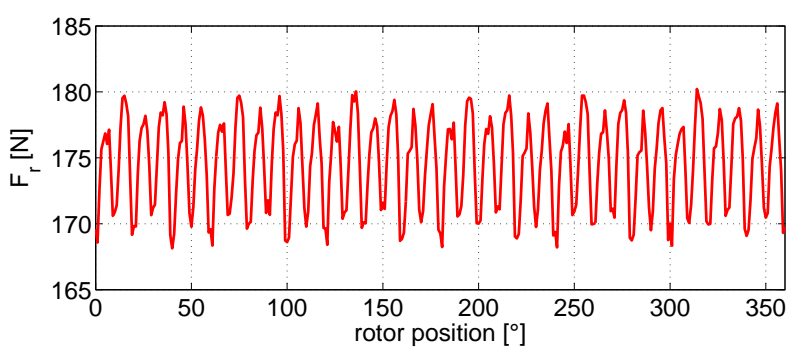

(b) SPM motor.

Fig. 16: The magnetic force behavior versus the rotor position for both 36-slot six-pole (a) PMAREL and (b) SPM motors, with static eccentricity case.

winding arrangement, and 3) different number of poles. As expected, the PMAREL motor is the worst for all current angles range, as in static eccentricity case. Considering the FSCW, the radial force on SPM and PMAREL motor is 113 $\mathrm{N}$ and $282 \mathrm{~N}$, respectively. Comparing six pole motors, the radial force on SPM and PMAREL motor is $179 \mathrm{~N}$ and 1288 $\mathrm{N}$, respectively. As a consequence, the PMAREL motor is the worst motor in case of dynamic eccentricity, as well.

Furthermore, Fig. 17 shows the impact of the static and dynamic eccentricity on the electromagnetic torque of both motors. It is noted that, there are negligible effect of eccentricity on the torque. The impact of eccentricity on the flux linkage in $d$ and $q$ axes is shown in Fig. 17 for both motors. It is noted that, There are slight reduction in $d$-axis in case of the PMAREL motor. There are negligible effect on the $d$ and $q$ axes flux linkage of the SPM motor. This conclusion is useful from the control point of view because it gives an indication of how much the $d$ and $q$ axes inductances lookup table of those machines is affected by the eccentricity.

\section{Comparison in combined eccentricity case}

The combined eccentricity is applied to the SPM motor with the same axis of rotation used for both other motors, as shown in Fig. 2 (c). The radial force acting on the rotor of the PMAREL motor is about $430 \%$ (using Ferrite PM) and $480 \%$ (using NdFeB PM) of that acting on the rotor of the SPM motor, respectively. The radial forces acting on each pole is computed, as reported in Table X. The most affected pole is the first pole, as occurs in the dynamic eccentricity. Once again, the same comparison is repeated in case of adopting FSCW, wide range of current angles, and different number of pole. It can be deduced that, the PMAREL motor is the worst in case of combined eccentricity, as well.

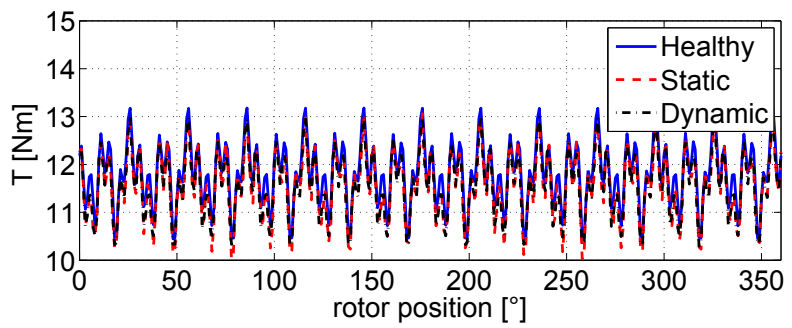

(a) PMAREL motor.

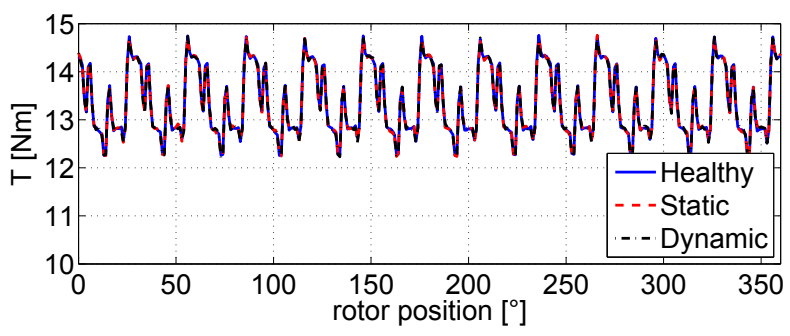

(b) SPM motor

Fig. 17: Torque versus rotor position of cylindrical and eccentric (a) PMAREL and (b) SPM motors.

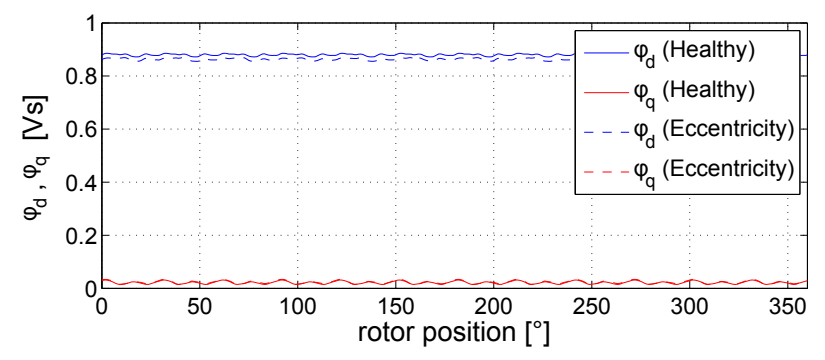

(a) PMARELmotor

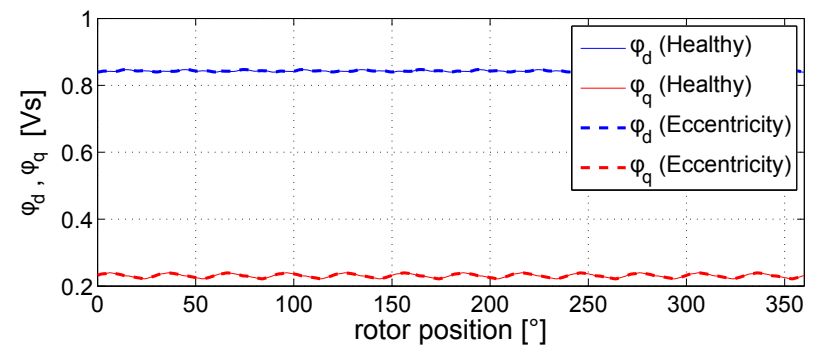

(b) SPM motor

Fig. 18: Flux linkage versus rotor position of cylindrical and eccentric (a) PMAREL and (b) SPM motors.

TABLE X: Radial forces acting on the poles of the SPM motor, with combined eccentricity, at $\theta_{m}=0^{\circ}$.

\begin{tabular}{cccc}
\hline \multicolumn{4}{c}{$F_{r}$ acting on the PMs $[N]$} \\
\hline POLE 1 & POLE 2 & POLE 3 & POLE 4 \\
\hline 647.9 & 584.8 & 536.1 & 593.0 \\
\hline
\end{tabular}

\section{StRUCtURAL ANALYSiS}

To evaluate the mechanical integrity of the rotor structure in healthy condition and under eccentricity, the mechanical stress and deformation in the rotor are predicted. Using electromag- 
netic FE analysis, the surface magnetic force density on the rotor are extracted and imported to mechanical FE analysis to compute the mechanical stress and deformation generated by these forces. In addition to the stress generated by the magnetic forces, the rotor is subjected to mechanical stresses generated due to the rotation, i.e. centrifugal forces. The rotor structural analysis are conducted when the rotor is under rotational forces only, magnetic forces only and both rotational and magnetic forces. The mechanical properties are listed in Table XI.

TABLE XI: Mechanical properties of the motor lamination.

\begin{tabular}{ccc}
\hline Properties & Unit & Value \\
\hline Mass density & $\mathrm{Kg} / m^{3}$ & 7650 \\
Young's modulus & $\mathrm{GPa}$ & 215 \\
Poisson's ratio & - & 0.3 \\
Yield strength & $\mathrm{MPa}$ & 370 \\
Tensile strength & $\mathrm{MPa}$ & 490 \\
\hline
\end{tabular}

The structural analysis has been conducted using ANSYS mechanical APDL solver. The boundary condition of the model is a fixed support at the inner rotor surface to simulate the contact with the shaft, whereas the load conditions are surface force density applied at the outer surface of the rotor, the forces are exported from ANSYS electronic workbench (Maxwell) electromagnetic FEA model, and applied rotational velocity of $5000 \mathrm{rpm}$. Quad mesh is used with different intensities being very fine in and around the inner and outer ribs, the total mesh elements are 232716 and total mesh nodes are 654646.

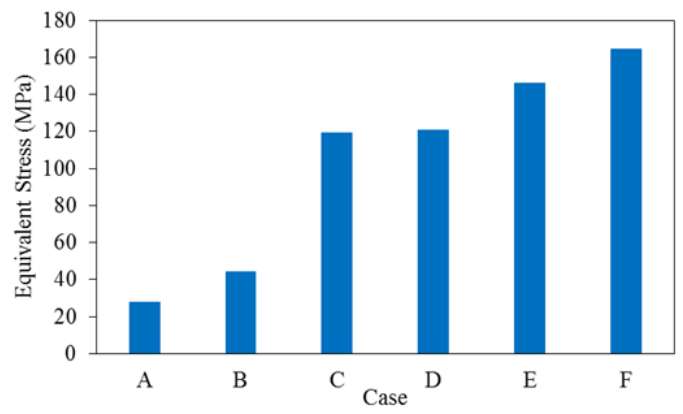

(a) Comparison of the maximum equivalent stress (MPa) of the six investigated cases (a to f).

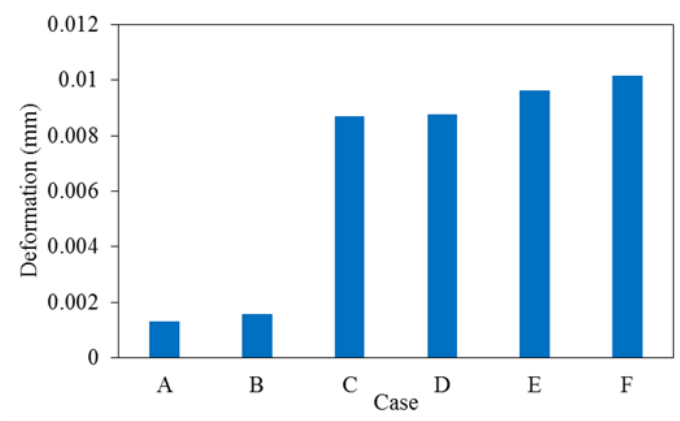

(b) Comparison of the maximum deformation ( $\mathrm{mm}$ ) of the six investigated cases (a to f).

Fig. 19: Comparison of (a) the maximum equivalent stress (MPa) and (b) the maximum deformation $(\mathrm{mm})$ of the six investigated cases ( A to F ).
The mechanical stress (von-Mises) generated due to magnetic forces are shown in case A and B of Fig. 19 (a) for healthy and eccentricity cases, respectively. Besides, the radial forces results from the rotational speed $(5000 \mathrm{rpm})$ are shown in case C and D of Fig. 19, for both cases, respectively. Consequently, the combination of both magnetic and rotational forces acting on the cylindrical and eccentric REL machines are shown in Case E and F of Fig. 19 (a), respectively. It is deduced that, eccentric rotor has higher mechanical stresses in the half near the eccentricity due to the higher magnetic forces. The maximum stress in the iron ribs is increased by $60 \%$.

In addition, the deformation generated due to magnetic forces for both healthy and eccentricity cases is presented in case A and B of Fig. 19 (b), respectively. In addition, the deformation results from the rotational speed force is presented in case C and D of Fig. 19 (b), for both healthy and eccentricity cases, respectively. Furthermore, case E and F of Fig. 19 (b) presents the deformation results from the combination of both magnetic and rotational forces acting on the cylindrical and eccentric REL machines rotors, respectively.

Since the maximum stress in the combined case of magnetic force and rotation in healthy and under eccentricity is significantly lower than the yield stress of the material, the deformations in the rotor due to these stress are elastic and therefore they are reversible once the stress are removed, i.e. the rotor operates safely at maximum speed and under extreme eccentricity. This is since the machine is well designed with high mechanical safety factor (from 2 to 3 ) taking in consideration the magnetic forces and the rotational stresses.

The mechanical stresses are calculated at the point of maximum net force, in both healthy and eccentric conditions. Nevertheless, the maximum mechanical stress might not occur at this point since the surface force density and consequently the mechanical stress are related to the magnetic flux paths and their alignment with the stator teeth. Similarly, the maximum stress when eccentricity occurs highly depends on the rotor angle where the eccentricity occurs. Additionally, rotor with small diameter and low speed will exhibit lower rotational stress and therefore the magnetic forces in healthy and eccentricity cases become the dominant and therefore need to be considered carefully in the designing stage.

Finally, a test bench has been designed in order to validate the prediction of the unbalanced magnetic forces [26], as shown in Fig. 20. The measured magnetic forces are compared with those of the FE analyses. Fig. 21 shows the comparison between the results of both analytical and FE models and the experimental test at different eccentricity values. As an example, eccentricity equal to $0.2 \mathrm{~mm}$ and $0.26 \mathrm{~mm}$ are considered. It is noted that there are a good agreement between the carried analyses and the experimental test.

\section{CONCLUSIONS}

This paper analyzes the impact of static, dynamic, and combined eccentricity on the radial force acting on the rotor of the REL, PMAREL, and SPM machines. Referring to the REL and PMAREL machines, the radial forces acting on 


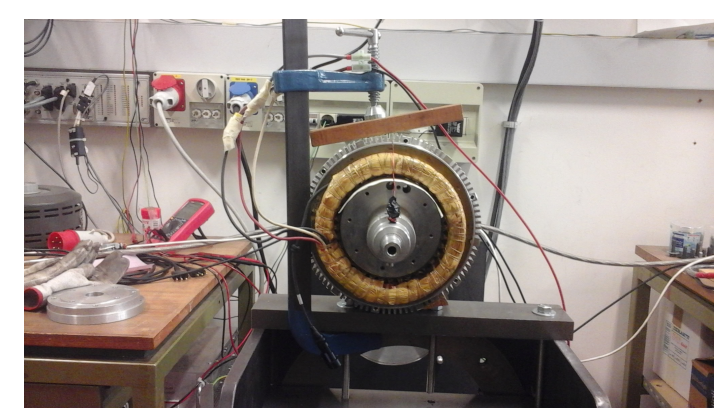

Fig. 20: The test bench structure.

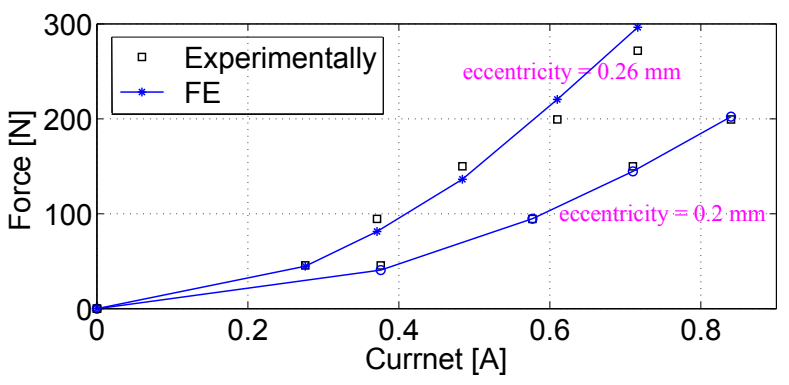

Fig. 21: The magnetic force versus the current, which results from the $\mathrm{FE}$ analysis, and experimental test at different eccentricity values $(0.2$ and $0.26 \mathrm{~mm})$.

rotor islands are computed. Different rotor geometries are considered. The impact of the dimension of the flux-barriers on the radial forces is highlighted. It is noted that the radial force acting on the asymmetric rotor is comparable to that acting on the symmetric rotor. There are no significant difference between the radial forces acting on both REL and PMAREL motors in different eccentricity cases, only (5 to $10 \%$ higher in case of $\mathrm{NdFeB}$ PMAREL motor, which means the forces are still comparable).

The Ferrite PMAREL and NdFeB PAMREL are compared with SPM machines, as shown in Table VII, in static eccentricity case. It is noted that, the radial force acting on PMAREL with Ferrite PMs machines is about $450 \%, 430 \%$, and $430 \%$ with respect to SPM machine, in case of static, dynamic, and combined eccentricity cases, respectively. Besides, the radial force acting on $\mathrm{NdFeB}$ PMAREL machines is about $510 \%, 480 \%$, and $480 \%$ with respect to SPM machine, in case of static, dynamic, and combined eccentricity cases, respectively. Therefore, the impact of the eccentricity on SPM machines is lower than that on REL, Ferrite, and NdFEB PMAREL machines, even if there are high radial forces acting on the rotor poles. This difference results from the specific geometrical features of both machines topologies, as: (a) the magnetic air-gap length of the SPM motor is higher than that of the REL and PMAREL motors due to the PMs sleeve and (b) based on the reluctance torque dependency of both REL and PMAREL machines, they are sensitive to the airgap length variation results from the eccentricity, with respect to the SPM machines.

Again, the comparison between PMAREL or REL with SPM motor is carried out at different current angles, stator windings arrangements, and different number of poles. It can be deduced that PMAREL or REL motor exhibit the highest forces for all previous conditions in different eccentricity scenarios.

Structural and deformation analyses of cylindrical and eccentric REL machine are applied. The mechanical stress due to the magnetic forces increases by $60 \%$ due to the eccentricity $(0.3 \mathrm{~mm})$. Although, the large rotor diameter and high rotational speed makes the stress generated by the centrifugal forces the dominant, however, the eccentricity still contributes a significant amount of mechanical stress and therefore needs to be considered in the designing stage.

Finally, this study helps the designers to define the tolerance of the selected laminations of those machines. Furthermore, the robust design of the rotor bearings against the vibration and noise for the three motors can be applied. Besides, the thickness of the rotor iron ribs of PMAREL and REL motor can be designed avoiding the over sizing of the safety factor.

\section{REFERENCES}

[1] I. Coenen, M. van der Giet, and K. Hameyer, "Manufacturing tolerances: Estimation and prediction of cogging torque influenced by magnetization faults," IEEE Transactions on Magnetics, vol. 48, no. 5, pp. 1932-1936, May 2012.

[2] D.-J. Kim, H.-J. Kim, J.-P. Hong, and C.-J. Park, "Estimation of acoustic noise and vibration in an induction machine considering rotor eccentricity," IEEE Transactions on Magnetics, vol. 50, no. 2, pp. 857860, Feb 2014.

[3] A. J. P. Ortega and L. Xu, "Investigation of effects of asymmetries on the performance of permanent magnet synchronous machines," IEEE Transactions on Energy Conversion, vol. 32, no. 3, pp. 1002-1011, Sept 2017.

[4] A. Smith and D. Dorrell, "Calculation and measurement of unbalanced magnetic pull in cage induction motors with eccentric rotors. i. analytical model," IEE Proceedings - Electric Power Applications, vol. 143, no. 3 , pp. 193-201, May 1996.

[5] G. Joksimovic, M. Durovic, J. Penman, and N. Arthur, "Dynamic simulation of dynamic eccentricity in induction machines-winding function approach," IEEE Transactions on Energy Conversion, vol. 15, no. 2, pp. 143-148, June 2000.

[6] U. Kim and D. Lieu, "Magnetic field calculation in permanent magnet motors with rotor eccentricity: without slotting effect," IEEE Transactions on Magnetics, vol. 34, no. 4, pp. 2243-2252, Jul 1998.

[7] U. Kim and D. Lieu, "Magnetic field calculation in permanent magnet motors with rotor eccentricity: with slotting effect considered," IEEE Transactions on Magnetics, vol. 34, no. 4, pp. 2253-2266, Jul 1998.

[8] M. Michon, R. Holehouse, K. Atallah, and J. Wang, "Unbalanced magnetic pull in permanent magnet machines," in 7th IET International Conference on Power Electronics, Machines and Drives (PEMD 2014), April 2014, pp. 1-6.

[9] D. Dorrell, M. Popescu, C. Cossar, and D. Ionel, "Unbalanced magnetic pull in fractional-slot brushless pm motors," in Industry Applications Society Annual Meeting, 2008. IAS '08. IEEE, Oct 2008, pp. 1-8.

[10] M. Michon, R. Holehouse, K. Atallah, and G. Johnstone, "Effect of rotor eccentricity in large synchronous machines," IEEE Transactions on Magnetics, vol. 50, no. 11, pp. 1-4, Nov 2014.

[11] H. Mahmoud and N. Bianchi, "Eccentricity in synchronous reluctance motors-part I: Analytical and finite-element models," IEEE Transactions on Energy Conversion, vol. 30, no. 2, pp. 745-753, June 2015.

[12] H. Mahmoud and N. Bianchi, "Eccentricity in synchronous reluctance motors-part II: Different rotor geometry and stator windings," IEEE Transactions on Energy Conversion, vol. 30, no. 2, pp. 754-760, June 2015.

[13] H. Mahmoud and N. Bianchi, "Nonlinear analytical model of eccentric synchronous reluctance machines considering the iron saturation and slotting effect," IEEE Transactions on Industry Applications, vol. 53, no. 3, pp. 2007-2015, May 2017.

[14] G. Pellegrino, A. Vagati, P. Guglielmi, and B. Boazzo, "Performance comparison between surface-mounted and interior pm motor drives for electric vehicle application," IEEE Transactions on Industrial Electronics, vol. 59, no. 2, pp. 803-811, Feb 2012.

[15] A. EL-Refaie and T. Jahns, "Comparison of synchronous pm machine types for wide constant-power speed range operation," in Conference Record of the Industry Applications. Fourtieth IAS Annual Meeting., vol. 2, Oct 2005, pp. 1015-1022 Vol. 2. 
[16] C. Hwang, C. Chang, S. Cheng, C. Chan, C. Pan, and T. Chang, "Comparison of performances between IPM and SPM motors with rotor eccentricity," Journal of Magnetism and Magnetic Materials, vol. 282, pp. 360 - 363, 2004, international Symposium on Advanced Magnetic Technologies.

[17] K.-T. Kim, K.-S. Kim, S.-M. Hwang, T.-J. Kim, and Y.-H. Jung, "Comparison of magnetic forces for IPM and SPM motor with rotor eccentricity," IEEE Transactions on Magnetics, vol. 37, no. 5, pp. 34483451 , Sep 2001

[18] T.-J. Kim, S.-M. Hwang, K.-T. Kim, W.-B. Jung, and C.-U. Kim, "Comparison of dynamic responses for IPM and SPM motors by considering mechanical and magnetic coupling," IEEE Transactions on Magnetics, vol. 37, no. 4, pp. 2818-2820, Jul 2001.

[19] N. Bianchi, H. Mahmoud, and S. Bolognani, "Fast synthesis of permanent magnet assisted synchronous reluctance motors," IET Electric Power Applications, vol. 10, no. 5, pp. 312-318, 2016.

[20] H. Mahmoud and N. Bianchi, "Comparison between synchronous machines with eccentricity: Reluctance and permanent magnets," in 2016 International Symposium on Power Electronics, Electrical Drives, Automation and Motion (SPEEDAM), June 2016, pp. 394-400.

[21] H. Mahmoud and N. Bianchi, "Comparison between synchronous reluctance and interior permanent magnet motors with eccentricity," in IEEE Workshop on Electrical Machines Design, Control and Diagnosis (WEMDCD), March 2015, pp. 22-27.

[22] N. Bianchi, S. Bolognani, D. Bon, and M. PrÃ", "Rotor flux-barrier design for torque ripple reduction in synchronous reluctance and $\mathrm{pm}-$ assisted synchronous reluctance motors," IEEE Transactions on Industry Applications, vol. 45, no. 3, pp. 921-928, May 2009.

[23] N. Bianchi, S. Bolognani, D. Bon, and M. Pre "Torque Harmonic Compensation in a Synchronous Reluctance Motor,"in IEEE Transactions on Energy Conversion, vol. 23, no. 2, pp. 466-473, June 2008

[24] N. Bianchi, S. Bolognani, D. Bon, and M. Pre "Rotor Flux-Barrier Design for Torque Ripple Reduction in Synchronous Reluctance and PM-Assisted Synchronous Reluctance Motors," in IEEE Transactions on Industry Applications, vol. 45, no. 3, pp. 921-928, May-June 2009.

[25] H. Mahmoud and N. Bianchi, "Analytical comparison of synchronous reluctance and surface permanent magnet machines with rotor eccentricity," in Energy Conversion Congress and Exposition (ECCE), 2015 IEEE (WEMDCD), , Sept. 2015, pp. 1765-1772.

[26] H. Mahmoud,"Synchronous Reluctance Machines: Eccentricity Analysis and Design Criteria," Ph.D. dissertation, Padova, Italy, 2017.

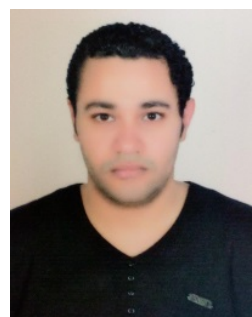

Hanafy Mahmoud received the bachelor's degree and the M.Sc. degree in electrical engineering in 2009 and 2012 respectively, from Cairo University, Cairo, Egypt. During his M.Sc. period he worked on faults detection and performance analysis of the induction machines. He received his a $\mathrm{PhD}$ degree from Padova University, Italy. He became teaching assistant in 2009, a Lecturer in electrical machines, in 2018 at Cairo university. Now, he is a Research Fellow at the PEMC group, Department of Electrical and Electronic Engineering, Nottingham University, UK. His research activities deals with the analysis of synchronous permanent magnet and reluctance machines, focusing on analytical and finite element modeling, faulty conditions analyses. Besides, his current research interests are high efficiency machine design for the advanced propulsion systems for Automotive, traction, and aerospace applications, as well as analytical modeling of various electrical machines.

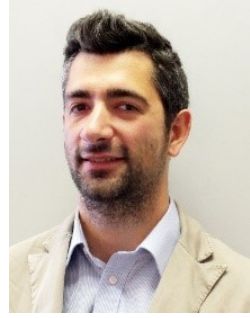

Michele Degano (M'15) received the Laurea degree in electrical engineering from the University of Trieste, Trieste, Italy, in 2011, and the Ph.D. degree in industrial engineering from the University of Padova, Padova, Italy, in 2015. During his doctoral studies, he cooperated with several local companies for the design of permanent-magnet machines. In 2015, he joined the Power Electronics, Machines and Control Group, The University of Nottingham, Nottingham, U.K., as a Research Fellow, where he is currently an Assistant Professor teaching advanced courses on electrical machines. His main research interests include design and optimization of permanent-magnet machines, reluctance and permanent-magnet-assisted synchronous reluctance motors through genetic optimization techniques, for automotive and aerospace applications, ranging from small to large power.

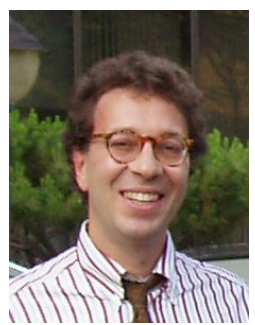

Nicola Bianchi (M'98-SM'09-F'14) received the M.Sc. and Ph.D. degrees in electrical engineering from the University of Padova, Padua, Italy, in 1991 and 1995 , respectively

In 1998, he joined the Department of Electrical Engineering, University of Padova, as an Assistant Professor. Since 2005, he has been an Associate Professor of electrical machines, converters, and drives. His activity is conducted in the Electric Drive Laboratory, Department of Electrical Engineering, University of Padova.

His teaching activity deals with the design methods of electrical machines, where he introduced the finite-element analysis of machines. He is the author or coauthor of several scientific papers and international books on electrical machines and drives. He is recipient of five awards for best conference and journal papers

His research activity is in the field of design of electrical machines, particularly for drive applications, in which he is responsible for various projects for local and foreign industries.

$\mathrm{He}$ is an IEEE Fellow member and a member of the Electric Machines Committee and the Electrical Drives Committee of the IEEE Industry Applications Society. He served as technical program chair for IEEE ECCE 2014 and is Associate Editor of IEEE Trans on IA and IET-EPA proceedings.

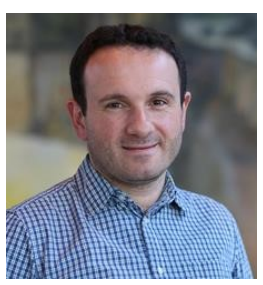

Chris Gerada (M'05-SM'12) received the Ph.D. degree in numerical modelling of electrical machines from The University of Nottingham, Nottingham, U.K., in 2005. He was a Researcher with The University of Nottingham, working on highperformance electrical drives and on the design and modelling of electromagnetic actuators for aerospace applications. Since 2006, he has been the Project Manager of the GE Aviation Strategic Partnership. In 2008, he became a Lecturer in electrical machines, in 2011, as an Associate Professor, and in 2013, a Professor at The University of Nottingham. His main research interests include the design and modelling of high-performance electric drives and machines. Prof. Gerada serves as an Associate Editor for the IEEE TRANSACTIONS ON INDUSTRY APPLICATIONS and is the Chair of the IEEE Industrial Electronics Society Electrical Machines Committee.

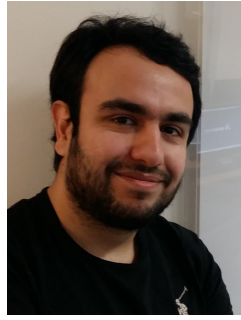

Mahir Al-ani received the bachelor's degree and the $\mathrm{PhD}$ degrees in electrical engineering in 2010 and 2014, respectively, from the University of Sheffield, UK. From 2014 to 2017 he was a research fellow at the turbocharger research institute at the University of Huddersfield, UK. He is current a research fellow at the University of Nottingham. His main research interest are permeant magnet machines and highspeed machines for automotive aplications. 